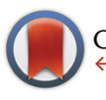

CrossMark \& click for updates

Cite this: Dalton Trans., 2015, 44 20745

Received 11th September 2015, Accepted 13th October 2015

DOI: 10.1039/c5dt03551a

www.rsc.org/dalton

\title{
Iron-catalysed homo- and copolymerisation of propylene: steric influence of bis(imino)pyridine ligands $\uparrow$
}

\author{
Takafumi Kawakami, Shingo Ito and Kyoko Nozaki*
}

A series of iron complexes bearing a bis(imino)pyridine ligand were synthesised and examined as precatalysts for homopolymerisation of propylene. The alkyl substituents attached to the aryl group on the imine nitrogen atoms significantly affected the catalytic activity and molecular weight of the obtained polypropylenes. Copolymerisation of propylene and various allyl comonomers catalysed by iron/bis(imino)pyridine was also investigated.

\section{Introduction}

Polypropylene is one of the most widely used polyolefins owing to its excellent bulk properties, easy processability, and low manufacturing costs; thus, tens of millions of tons per year are produced worldwide. ${ }^{1}$ Despite its inherent advantages, the nonpolar nature of polypropylene often leads to poor surface and material properties due to the absence of any polar functional group in its structure. To improve these properties, post-polymerisation functionalisation by radical or plasma methods ${ }^{2}$ is generally used to produce functional polypropylenes bearing polar functional groups. However, the inert nature of polypropylene requires harsh conditions for functionalisation, makes it difficult to control the polymer composition and structures, and limits the variety of functional groups introduced.

An ideal process for synthesising functionalised polypropylenes would be the copolymerisation of propylene and polar olefins bearing functional groups. Although industrial production of polypropylene is usually accomplished using earlytransition-metal catalysts, these catalysts are easily deactivated in the presence of polar functional groups. During the last two decades, therefore, group-10-metal catalysts bearing an $\alpha$-diimine ${ }^{3}$ or a phosphine-sulfonate ligand ${ }^{4}$ have attracted significant attention because their high functional group tolerance enables successful copolymerisation of ethylene and polar monomers. ${ }^{5}$ When these group-10-metal catalysts are

Department of Chemistry and Biotechnology, Graduate School of Engineering, The University of Tokyo, 7-3-1 Hongo, Bunkyo-ku, Tokyo 113-8656, Japan.

E-mail:nozaki@chembio.t.u-tokyo.ac.jp

$\dagger$ Electronic supplementary information (ESI) available: Experimental details; characterization of ligands, complexes, and polymers; crystallographic data for complexes. CCDC 1416774-1416776. For ESI and crystallographic data in CIF or other electronic format see DOI: 10.1039/c5dt03551a

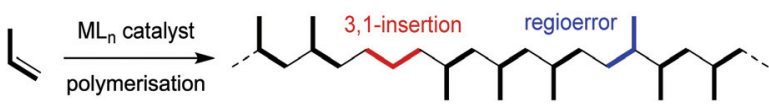

Scheme 1 Structural errors of polypropylene in metal-catalysed propylene polymerisation.

applied to propylene polymerisation, however, it is usually difficult to control the regiochemistry in the propylene insertion step. Propylene polymerisation by late-transition-metal catalysts generally affords amorphous polymers, mainly because of "chain-straightening" (red in Scheme 1) caused by formal 3,1-insertion through the sequence of 2,1-insertion of propylene, $\beta$-hydride elimination, and subsequent re-insertion in the opposite direction. ${ }^{3,6}$ Another potential problem is propylene insertion with the opposite regioselectivity, producing a head-to-head or tail-to-tail irregular sequence (blue in Scheme 1). In that sense, the significant advances in group-10metal catalysts are the development of the $C_{2}$-symmetric $\alpha$-diimine nickel complex, reported by Cherian et al., which produces highly isotactic polypropylene (iPP) at $-78{ }^{\circ} \mathrm{C},{ }^{7}$ and the $\alpha$-keto- $\beta$-diimine nickel complex, reported by Azoulay et al., which produces iPP at $-60{ }^{\circ} \mathrm{C} .{ }^{8}$ They required extremely low temperature to suppress formal 3,1-insertion and attain high isotactic selectivity. Recently, our group developed regioregular propylene polymerisation and propylene/polar monomer copolymerisation using palladium/imidazo[1,5-a]quinolin-9olate-1-ylidene (IzQO) complexes, ${ }^{9}$ in which formal 3,1-insertion was suppressed even at high temperature. However, stereoregularity (tacticity) was not controlled to give atatic polypropylenes.

In this context, iron(II)/bis(imino)pyridine complexes ${ }^{10}$ are an important class of catalysts that successfully promote olefin polymerisation without formal 3,1-insertion of propylene. Small and Brookhart ${ }^{11}$ and Pellecchia, et al. ${ }^{12}$ independently 
reported that the iron complexes show unique catalytic activity for propylene polymerisation to produce iPPs with molecular weights of $0.6-8.8 \times 10^{3}$ and isotactic selectivity of up to $\mathrm{mmmm}=67 .{ }^{11}$ After these seminal studies, a range of bis(imino)pyridine ligands and their iron complexes were designed and synthesised to investigate the effect of changing the substituents, especially those attached to the aniline moiety, on polymerisation. ${ }^{13}$ Most of the studies have focused on the oligo- and polymerisation of ethylene, and much less attention has been paid to those of propylene and higher olefins. ${ }^{14,15}$ We previously reported that, in ethylene polymerisation by palladium/phosphine-sulfonate catalysts, the introduction of bulky substituents on the phosphorus moiety dramatically increased the molecular weight. ${ }^{16} \mathrm{~A}$ plausible explanation for the increase in molecular weight is the steric congestion in the axial positions of the metal center, which could suppress chain transfer reactions. ${ }^{16,17}$ Motivated by these results, we hypothesized that the introduction of bulky substituents on bis(imino)pyridine ligands ${ }^{18}$ may affect the molecular weight as well as the tacticity of obtained polypropylene.

Another important requirement for improved utility of latetransition-metal polymerisation catalysts is copolymerisability with other comonomers. However, iron-catalysed copolymerisation of propylene with other olefinic comonomers has never been achieved. Boone et al. provided an important clue by investigating the copolymerisation of ethylene with vinyl chloride or vinyl acetate by iron(II)/bis(imino)pyridine catalysts. ${ }^{19}$ The attempted copolymerisation with deuterium-labeled vinyl chloride $\left(\mathrm{CD}_{2}=\mathrm{CDCl}\right)$ or vinyl acetate $\left(\mathrm{CD}_{2}=\mathrm{CDOAc}\right)$ resulted in the formation of polyethylene bearing a $-\mathrm{CD}=\mathrm{CD}_{2}$ group as the terminating group in the polyethylene chain. These observations suggested that polymerisation was terminated via $\beta$-FG elimination ( $\mathrm{FG}=$ functional group) after the insertion of comonomers. Hence, it would be necessary to use appropriate comonomers that resist $\beta$-FG elimination. We focused on allyl monomers, $\mathrm{CH}_{2}=\mathrm{CHCH}_{2} \mathrm{FG}$, because the presence of a methylene group between the carbon-carbon double bond and the functional group may be effective for suppressing chain termination by functional group elimination. ${ }^{9,16,20}$

Herein, we report the synthesis of a series of iron complexes bearing a bis(imino)pyridine ligand with various aryl groups and their catalytic performance in the polymerisation of propylene. We discuss mainly the effect of elongated alkyl substituents on the catalytic activity, molecular weight, and tacticity. We also report our investigation of iron-catalysed copolymerisation of propylene with various allyl monomers.

\section{Results and discussion}

A series of bis(imino)pyridine ligands bearing different aryl substituents on the imine nitrogen atoms (Fig. 1, 1a-i) were synthesised by a condensation reaction of 2,6-diacetylpyridine and the corresponding aniline ${ }^{21}$ using a typical procedure. Subsequent complexation of these ligands with iron(II)
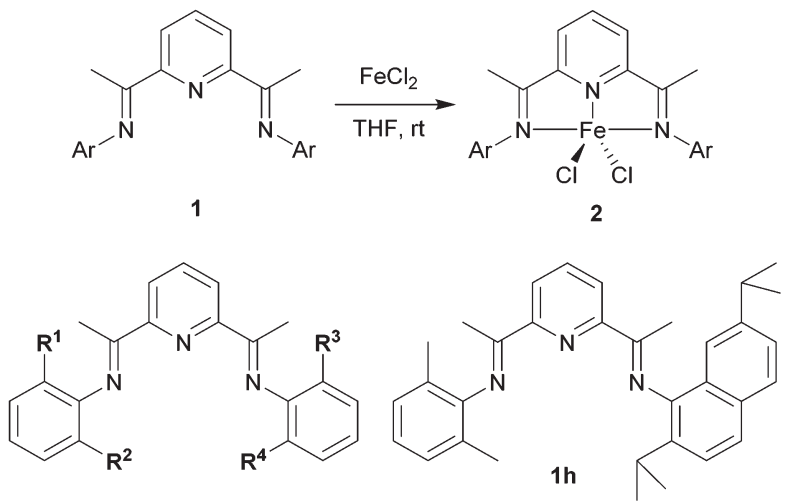

1a: $R^{1}=R^{2}=R^{3}=R^{4}=M e$

1b: $\mathrm{R}^{1}=\mathrm{R}^{2}=\mathrm{R}^{3}=\mathrm{R}^{4}=i-\mathrm{Pr}$

1c: $R^{1}=R^{2}=R^{3}=R^{4}=3$-pen

1d: $R^{1}=R^{2}=R^{3}=R^{4}=4$-hep

1e: $R^{1}=R^{2}=R^{3}=R^{4}=$ dmhep

1f: $\mathrm{R}^{1}=\mathrm{R}^{2}=\mathrm{Me} ; \mathrm{R}^{3}=\mathrm{R}^{4}=i-\mathrm{Pr}$

1g: $R^{1}=R^{3}=M e ; R^{2}=R^{4}=3$-pen

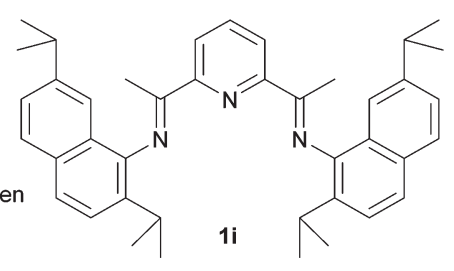

Fig. 1 Synthesis of iron complexes 2 bearing a bis(imino)pyridine ligand 1. Abbreviations: $\mathrm{Me}=$ methyl; $\mathrm{i}-\mathrm{Pr}=$ isopropyl; 3-pen = pentan-3-yl; 4-hep = heptan-4-yl; dmhep = 2,6-dimethylheptan-4-yl.

chloride in tetrahydrofuran afforded the corresponding iron complexes 2 , and their structures were confirmed by elemental analysis, electrospray-ionization (ESI) mass analysis, and X-ray crystallographic analysis: ${ }^{22}$ Ligands $\mathbf{1 a}-\mathbf{d}$ and $\mathbf{1} \mathbf{f}-\mathbf{i}$ were readily transformed to the iron complexes $\mathbf{2} \mathbf{a}-\mathbf{d}$ and $\mathbf{2} \mathbf{f}-\mathbf{i}$, respectively, in good yields (80-96\%), whereas the complexation of 1e did not afford complex $2 \mathrm{e}$ even at a higher temperature of $60{ }^{\circ} \mathrm{C}$. The reason could be that the 2,6-dimethylheptan-4-yl (dmhep) groups around the coordination site of the ligand are sterically too bulky. The introduced longer alkyl chains increased the solubility of complexes $\mathbf{2 a - d}$ and made them less crystalline. The structure of $\mathbf{2 c}$ was confirmed by X-ray crystallographic analysis of blue single crystals obtained by recrystallisation from dichloromethane/pentane (Fig. 2A). The iron center of $2 \mathrm{c}$ has a distorted square pyramidal geometry, like reported complexes such as $\mathbf{2 b}$ (Table 1 ). ${ }^{10}$ The recrystallisation of $\mathbf{2 d}$ under the same conditions afforded three types of single crystals, which were blue, yellow, or red. The blue single crystals were found to be dichloride $\mathbf{2 d}$, and the red ones were found to be the $\mathrm{Fe}(\mathrm{II}) \mathrm{ClOH}$ complex linked to an $\mathrm{FeCl}_{3}$ moiety via a bridging $\mathrm{OH}$ group (2d'), presumably generated by disproportionation of $2 \mathbf{d}^{11}{ }^{11}$ The formation of $2 \mathbf{d}^{\prime}$ could be explained by reaction with the solvent and/or moisture during recrystallisation. Considering the mass balance of the iron components, the yellow crystals were assumed to be ligand $\mathbf{1 d}$. The crystal structure of $\mathbf{2} \mathbf{d}^{\prime}$ (Fig. 2B) is closely related to those of $\mathbf{2 b}$ and $2 \mathbf{c}$ except for the difference in the lengths of the $\mathrm{Fe}-\mathrm{Cl}$ and $\mathrm{Fe}-\mathrm{O}$ bonds. Regarding the bis(imino)pyridineFe moiety of $2 \mathbf{d}^{\prime}$, the bond length of $\mathrm{Fe}-\mathrm{N} 1$ (pyridine) is 2.054(6) $\AA$, and those of $\mathrm{Fe}-\mathrm{N} 2$ and Fe-N3(imine) are 2.225-2.236 $\AA$, which are within the common range of related 

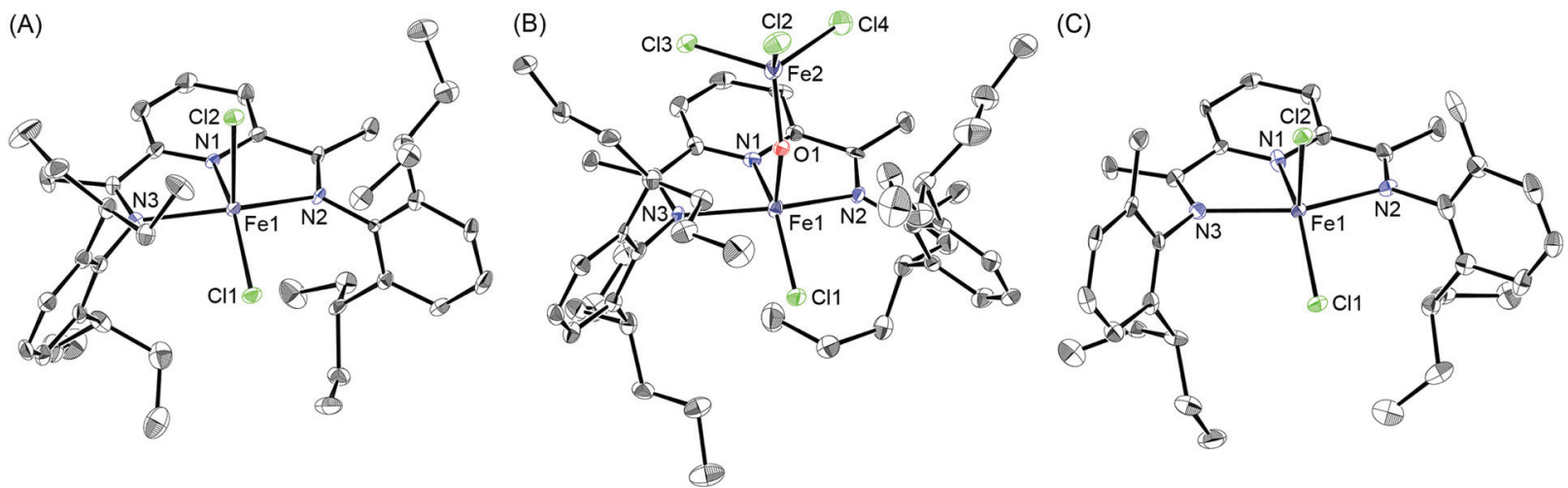

Fig. 2 X-ray structures of iron/2,6-bis(imino)pyridine complexes (A) $\mathbf{2 c}$, (B) $\mathbf{2 d}$ ', and (C) $\mathbf{2 g}$ with $50 \%$ probability of thermal ellipsoids. Hydrogen atoms and solvent molecules are omitted for clarity.

Table 1 Representative bond lengths $(\AA \AA)$ and angles $\left(^{\circ}\right)$ of iron/bis(imino)pyridine complexes

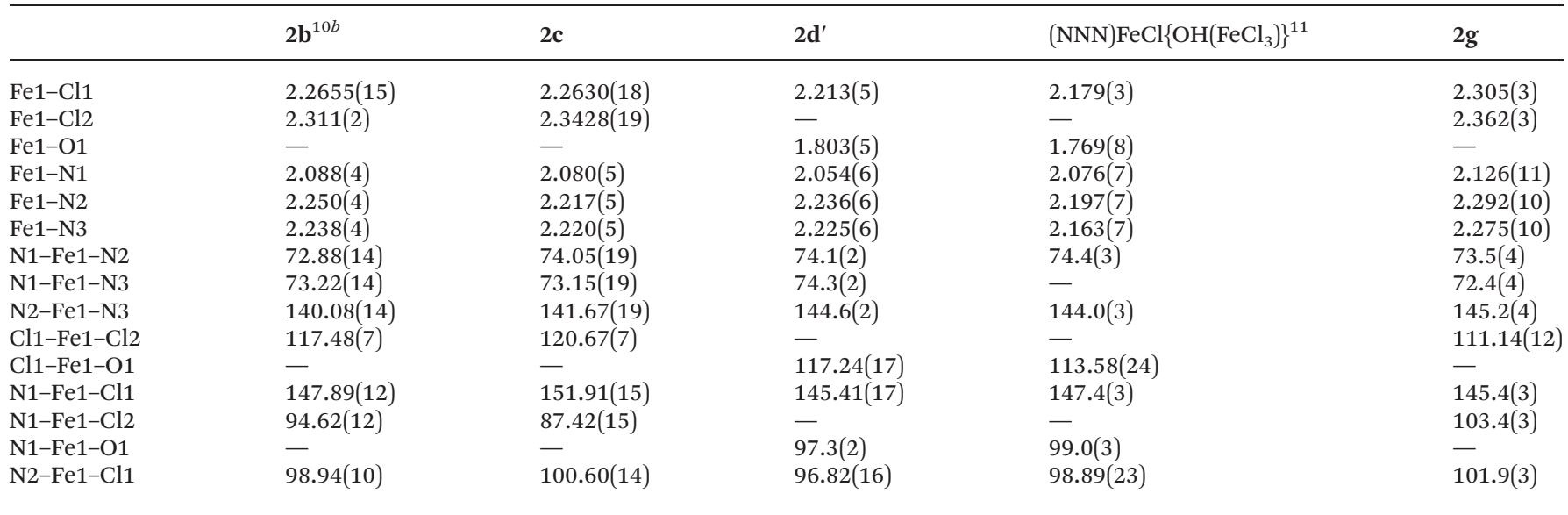

compounds. ${ }^{10,11,23}$ The phenyl planes on the imine nitrogen atoms are nearly orthogonal to the plane of the pyridine ring, with dihedral angles of $71^{\circ}$ and $86^{\circ}$. These values are slightly smaller than those of the reported Fe(II)ClOH complex bearing isopropyl and methyl groups on the phenyl ring $\left(83^{\circ}\right.$ and $\left.89^{\circ}\right),{ }_{11}^{11}$ presumably owing to steric repulsion between the heptan-4-yl groups and the $\mathrm{Fe}(\mathrm{OH}) \mathrm{FeCl}_{3}$ moiety. Although the long alkyl substituents are placed as it surrounds the iron center, no intramolecular $\mathrm{H}-\mathrm{Cl}$ bonding interaction was observed. The structure around the iron center of $\mathbf{2} \mathbf{d}^{\prime}$ is similar to that of the reported $\mathrm{Fe}(\mathrm{II}) \mathrm{ClOH}$ complex: ${ }^{11}$ For example, the N1-Fe1-Cl1, N1-Fe1-O1, and N2-Fe1-N3 angles of $2 \mathbf{d}^{\prime}$ are 145.41(17), 97.3(2), and 144.6(2) ${ }^{\circ}$, respectively, whereas those of the reported $\mathrm{Fe}(\mathrm{II}) \mathrm{ClOH}$ complex are 147.4(3), 99.0(3), and $144.0(3)^{\circ}$, respectively. In the case of $2 \mathrm{~g}$ (Fig. 2C), which has unsymmetrically substituted aryl groups on both imine nitrogen atoms, complexation with iron(II) chloride could form two possible isomeric complexes that have $C_{2}$ or $C_{\mathrm{S}}$ symmetry, but the $C_{\mathrm{S}}$ symmetric configuration was confirmed by X-ray analysis for complex $2 \mathrm{~g}$.

Homopolymerisation of propylene was investigated using iron complexes 2 activated by modified methylaluminoxane
(MMAO) (Table 2). Because the lifetime of the iron catalyst is significantly affected by reaction temperature, ${ }^{11}$ we performed propylene polymerisation at $-20^{\circ} \mathrm{C}$. First, complexes $2 \mathrm{a}$ and $\mathbf{2 b}$, originally reported by Brookhart and his coworkers, ${ }^{11}$ were examined for propylene polymerisation and found to give catalytic activities of 72 and $200 \mathrm{~g} \mathrm{mmol}^{-1} \mathrm{~h}^{-1}$, respectively (entries 1 and 2). Of these two complexes, $2 \mathbf{b}$, bearing bulkier isopropyl substituents, afforded polypropylene with a higher molecular weight $\left(M_{\mathrm{n}}=4.7 \times 10^{3}\right)$ than that of $2 \mathrm{a}$, bearing methyl groups $\left(M_{\mathrm{n}}=1.6 \times 10^{3}\right) \cdot{ }^{11}$ Thus, we hypothesised that the longer alkyl chain could block the axial position of the iron center and inhibit $\beta$-hydride elimination to afford high-molecular-weight polypropylenes. ${ }^{16,17}$ Next, we examined catalysts 2c and 2d, which have longer alkyl substituents (entries 3 and 4), and found that these catalysts were less active by 2 orders of magnitude than less bulky catalysts such as $\mathbf{2 b}$. This suggests that the substituents also severely inhibited the coordination and insertion of propylene. Notably, among the catalysts examined in this study, catalyst 2c yielded the highest isotacticity of $60 \%$ (entry 3 ). ${ }^{24}$ Next, we focused on ligands bearing unsymmetrically substituted aryl groups. Polymerisation in the presence of complex $\mathbf{2 f}$, bearing 
Table 2 Propylene polymerisation by iron catalysts ${ }^{a}$

\begin{tabular}{|c|c|c|c|c|c|c|}
\hline & & & $\begin{array}{c}\text { iron catalyst } \\
\text { MMAO }\end{array}$ & & & \\
\hline Entry & Catalyst & $\begin{array}{l}\text { Yield }^{b} \\
(\mathrm{~g})\end{array}$ & $\begin{array}{l}\text { Activity } \\
\left(\mathrm{g} \mathrm{mmol}^{-1}\right. \\
\left.\mathrm{h}^{-1}\right)\end{array}$ & $\begin{array}{l}M_{\mathrm{n}}{ }^{c} / \\
10^{3}\end{array}$ & $\begin{array}{l}M_{\mathrm{W}} / \\
M_{\mathrm{n}}{ }^{c}\end{array}$ & {$[\mathrm{mmmm}]^{d}$} \\
\hline | & $2 a$ & 1.4 & 72 & 1.6 & 2.1 & 39 \\
\hline $2^{f}$ & $2 b$ & 1.0 & 200 & $4.7(9.0)$ & 2.5 & 54 \\
\hline${ }_{3} e$ & $2 c$ & 0.065 & 0.82 & 3.4 & 2.4 & 60 \\
\hline $4^{e}$ & $2 d$ & 0.041 & 0.76 & 4.5 & 2.1 & 53 \\
\hline $5^{f}$ & $2 f$ & 1.5 & 290 & 4.1 & 2.3 & 57 \\
\hline & $2 \mathrm{~g}$ & 0.68 & 34 & $6.6(9.5)$ & 2.9 & 54 \\
\hline $7^{f}$ & $2 \mathrm{~h}$ & 1.8 & 350 & 3.2 & 2.6 & 52 \\
\hline & $2 \mathrm{i}$ & 1.3 & 67 & 3.2 & 4.1 & 59 \\
\hline
\end{tabular}

${ }^{a}$ A mixture of catalyst $2(10 \mu \mathrm{mol})$, MMAO $(8 \mathrm{mmol})$ and propylene in toluene/hexane $(15 \mathrm{~mL})$ was stirred in a $50 \mathrm{~mL}$ autoclave for $2 \mathrm{~h}$ at $-20{ }^{\circ} \mathrm{C} .{ }^{b}$ Isolated yields after washing with $\mathrm{MeOH} / 1 \mathrm{M} \mathrm{HCl}$ aq. mixture and acetone. ${ }^{c}$ Molecular weights determined by size exclusion chromatography (SEC) using polystyrene standards. Molecular weights in parenthesis are determined by ${ }^{1} \mathrm{H}$ NMR analysis. ${ }^{d}$ Ratio of meso pentad determined by ${ }^{13} \mathrm{C}$ NMR analysis. ${ }^{25} e^{e} 40 \mu \mathrm{mol}$ of catalyst was used. ${ }^{f}$ Reaction was carried out for $1 \mathrm{~h}$ with $5 \mu \mathrm{mol}$ of catalyst because of stirring difficulty.

a 2,6-diisopropylphenyl group on the nitrogen atom of one imine and a 2,6-dimethylphenyl group on the nitrogen atom of the other imine (entry 5), afforded polypropylene with higher catalytic activity than those obtained using symmetrically substituted groups. ${ }^{11}$ In the polymerisation by complex $2 \mathrm{~g}$, bearing two 2-methyl-6-(pentan-3-yl)phenyl groups (entry 6), the catalytic activity was higher than those of four 3-pentylsubstituted complex 2c (entry 3), but lower than those of four methyl-substituted complex $\mathbf{2 a}$ (entry 1 ) and unsymmetrically substituted complex 2 f (entry 5), It should be noted that $\mathbf{2 g}$ produced the highest molecular weights of the polypropylenes. We also tried polymerisation by complexes $2 \mathbf{h}$ and $2 \mathbf{i}$ (entries 7 and 8), bearing 2,7-diisopropylnaphthyl groups on the imine nitrogen atoms. Polymerisation by $\mathbf{2 h}$ gave the highest catalytic activity (entry 7 ), whereas that with $2 \mathbf{i}$ gave lower activity (entry 8). The molecular weights of the polymers remained modest, presumably because the 2,7-diisopropylnaphthyl group is assumed to be smaller than the 2,6-diisopropylphenyl group in a proximal position.

The microstructures of the obtained polypropylenes were investigated by nuclear magnetic resonance (NMR) analyses. In ${ }^{13} \mathrm{C}$ NMR spectra of the polypropylenes obtained using $\mathbf{2 b}$ (entry 2; Fig. $\mathrm{S} 4$ and $5 \dagger$ ) and $2 \mathrm{~g}$ (entry 6; Fig. $\mathrm{S} 13 \dagger$ ), the signals corresponding to methine $(\mathrm{CH})$, methylene $\left(\mathrm{CH}_{2}\right)$, and methyl $\left(\mathrm{CH}_{3}\right)$ carbons were observed as $1: 1: 1$, respectively. The signals generated by formal 3,1-insertion of propylene, which are supposed to appear at 27.5-27.6 $\mathrm{ppm}^{26}$ or 25.2-25.4 ppm, ${ }^{27}$ were not observed. On the basis of these results, we concluded that the iron complexes produce polypropylene without observable 3,1-insertion of propylene. Regarding the head-to-tail regioselectivity, the signals of regioerror structures caused by head-to-head and tail-to-tail insertion of propylene (15-18 ppm, 34-38 ppm, 40-44 ppm $)^{11,25,26,28,29}$ were observed in the case of less sterically hindered catalysts $\mathbf{2 a}$ and $\mathbf{2 h}$ (Fig. S2 and S15 $\dagger$ ), which afforded low-molecular-weight polymers, whereas the regio-

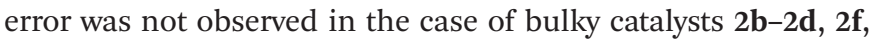
$2 \mathrm{~g}$, and $2 \mathbf{i}$. ${ }^{13} \mathrm{C}$ NMR analyses revealed that all the catalysts examined in this study produced isotactic polypropylene with up to $60 \%$ meso pentad content. The low content of the $r r$ diad sequence and almost 1-to-1 ratio of the $\mathrm{mmmr}$ and $\mathrm{mmrm}$ pentad sequences suggest that the chain-end control mechanism is predominant in this propylene polymerisation, as previously reported. ${ }^{11}$ These results indicate that the elongation and/or desymmetrisation of substituents do not significantly influence the polypropylene microstructure.

The chain-end structures of the obtained polymers were also elucidated. The major olefinic signals observed in the ${ }^{13} \mathrm{C}$ NMR (around 138 and $116 \mathrm{ppm}$ ) and ${ }^{1} \mathrm{H}$ NMR (around 5.9 and $5.1 \mathrm{ppm})^{30}$ spectra corresponded to the presence of an allyl group $\left(\mathrm{CH}_{2}=\mathrm{CHCH}_{2}-\right)$, which could be generated by 2,1-insertion of propylene followed by $\beta$-hydride elimination. ${ }^{29 a}$ The molecular weights of polypropylene determined from the ${ }^{1} \mathrm{H}$ NMR spectra assuming the allyl group is the only termination chain end were found to be $9.0 \times 10^{3}$ (entry 2) and $9.5 \times 10^{3}$ (entry 6), which are significantly higher than those determined using gel permeation chromatography analysis, $4.7 \times 10^{3}$ and $6.6 \times 10^{3}$, respectively. This discrepancy could be explained by the presence of saturated alkyl groups as the termination chain end, which could be produced by chain transfer to the aluminum center of the cocatalyst and subsequent hydrolysis during polymerisation. As to the initiation process, there are six types of possible initiating groups generated by $1,2-$ or 2,1 insertion of propylene into $\mathrm{Fe}-\mathrm{H}, \mathrm{Fe}-\mathrm{Me}$, or $\mathrm{Fe}-i$-Bu bonds. In the ${ }^{13} \mathrm{C}$ NMR spectra (Fig. S5 $\dagger$ ), we observed only signals representing $n$-butyl and 3-methylbutyl groups generated by successive 1,2- and 2,1-insertion of propylene into $\mathrm{Fe}-\mathrm{H}$ and 2,1insertion of propylene into $\mathrm{Fe}-i$-Bu bonds, respectively, as the dominant initiation chain-end structures.

Copolymerisation of propylene with a range of allyl monomers was examined using catalyst $\mathbf{2 b}$ (Table 3 ). ${ }^{31}$ First, we investigated copolymerisation with polar monomers bearing $\mathrm{CH}_{2}=\mathrm{CHCH}_{2} \mathrm{OR}$ structures, such as allyl acetate (entries 1 and 2), allyl ether (entry 3), and allyl silyl ethers (entries 4 and 5), because the introduction of hydroxy groups into polyolefins is of significant importance. ${ }^{32}$ In all the attempts, however, the corresponding functionality was not incorporated. In the case of allyl acetate (entry 1), copolymerisation in the presence of $0.20 \mathrm{~mL}(1.9 \mathrm{mmol})$ of allyl acetate produced only polypropylene without any incorporation of allyl acetate. When an increased amount of allyl acetate $(0.80 \mathrm{~mL} ; 7.4 \mathrm{mmol})$ was used (entry 2), the production of polymer was completely suppressed. Note that the homopolymerisation of propylene was also significantly suppressed in the presence of ethyl acetate (4.1 mmol). ${ }^{33}$ Thus, we concluded that the intermolecular interaction between the ester functional group in the acetates and the iron center and/or cocatalyst, MMAO, retarded polymerisation. The attempted copolymerisation with allyl methyl 
Table 3 Copolymerisation of propylene and allyl monomers by iron complex $2 \mathbf{b}^{a}$

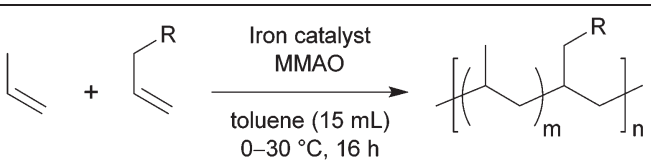

\begin{tabular}{|c|c|c|c|c|c|c|c|c|c|}
\hline Entry & $\begin{array}{l}\mathrm{R} \text { in } \\
\text { comonomer }\end{array}$ & $\begin{array}{l}\text { Comonomer } \\
(\mathrm{mL})\end{array}$ & $\begin{array}{l}\text { Propylene } \\
\text { (g) }\end{array}$ & $\begin{array}{l}T \\
\left({ }^{\circ} \mathrm{C}\right)\end{array}$ & $\begin{array}{l}\text { Yield }^{b} \\
(\mathrm{~g})\end{array}$ & $\begin{array}{l}\text { Activity } \\
\left(\mathrm{g} \mathrm{mmol}^{-1} \mathrm{~h}^{-1}\right)\end{array}$ & $\begin{array}{l}M_{\mathrm{n}} / 10^{3 c} \\
(\mathrm{~g} \mathrm{~mol}-1)\end{array}$ & $\begin{array}{l}M_{\mathrm{w}} /{ }^{c} \\
M_{\mathrm{n}}{ }^{2}\end{array}$ & $\begin{array}{l}\text { Incorp. }{ }^{d} \\
(\%)\end{array}$ \\
\hline 1 & $\mathrm{R}=\mathrm{OAc}$ & 0.20 & 9.4 & 30 & 2.7 & 8.5 & 3.3 & 6.9 & 0 \\
\hline 3 & $\mathrm{R}=\mathrm{OMe}$ & 0.40 & 9.2 & 30 & 0.37 & 1.1 & 3.7 & 2.1 & 0 \\
\hline 4 & $\mathrm{R}=\mathrm{OSi}^{t} \mathrm{BuMe}_{2}$ & 0.40 & 6.9 & 30 & 1.9 & 5.9 & 3.4 & 2.0 & 0 \\
\hline 5 & $\mathrm{R}=\mathrm{OSi}^{\mathrm{i}} \mathrm{Pr}_{3}$ & 0.40 & 9.2 & 30 & 2.7 & 8.4 & 2.4 & 2.0 & 0 \\
\hline 6 & $\mathrm{R}=\mathrm{Ph}$ & 0.40 & 5.7 & 30 & 2.3 & 7.2 & 0.97 & 2.1 & 1.4 \\
\hline 9 & $\mathrm{R}=\mathrm{Si}(\mathrm{OEt})_{3}$ & 0.40 & 11 & 0 & $0.44^{e}$ & 1.3 & 3.2 & 2.4 & 0.30 \\
\hline
\end{tabular}

${ }^{a}$ A mixture of catalyst $\mathbf{2 b}$, propylene and a comonomer in toluene $(15 \mathrm{~mL})$ in a $50 \mathrm{~mL}$ autoclave was stirred for 16 hours at an indicated temperature. ${ }^{b}$ Isolated yields after washing with $\mathrm{MeOH} / 1 \mathrm{M} \mathrm{HCl}$ aq. mixture and acetone. ${ }^{c}$ Molecular weights determined by SEC analysis using polystyrene standards. ${ }^{d}$ Molar incorporation ratios of comonomers determined by ${ }^{1} \mathrm{H}$ NMR analysis. ${ }^{e}$ Isolated yield after Soxhlet extraction with toluene.

ether and allyl silyl ethers promoted only the homopolymerisation of propylene, and the comonomers were not incorporated at all. Given that oxygen atoms in allyl ethers are known to coordinate to an aluminum cocatalyst, ${ }^{5 a}$ a possible explanation of the lack of incorporation of the comonomers is that bulky aluminum or silyl protecting groups retard the coordination of these comonomers than propylene.

In contrast, allylbenzene (entry 6$)^{34-36}$ and allylsilanes (entries 7-9) ${ }^{37-39}$ could be incorporated into the polypropylene chain. In the case of allylbenzene, copolymerisation of propylene with $0.40 \mathrm{~mL}(19 \mathrm{mmol})$ of allylbenzene afforded the corresponding copolymer with $1.4 \%$ comonomer incorporation. ${ }^{1} \mathrm{H}$ and ${ }^{13} \mathrm{C}$ NMR analyses revealed that all the phenyl groups introduced were incorporated into the chain ends of the obtained polypropylene (Fig. 3). This result could be explained by the following mechanism, which is shown in Scheme 2: propylene polymerisation proceeds via the

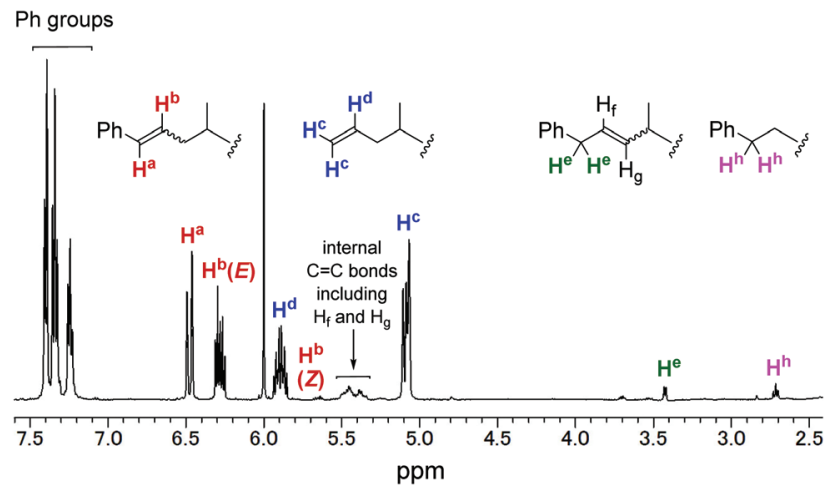

Fig. $3{ }^{1} \mathrm{H}$ NMR spectrum of propylene/allylbenzene copolymer (entry 6 in Table 2). 2,1-insertion mechanism, as proposed in the literature. ${ }^{11}$ Termination occurs by $\beta$-hydride elimination after 2,1 -insertion of propylene to form the allyl $\left(\mathrm{H}_{2}^{\mathrm{c}} \mathrm{C}=\mathrm{CH}^{\mathrm{d}} \mathrm{CH}_{2}{ }^{-}\right)$group, which was observed as one of the major chain ends in the ${ }^{1} \mathrm{H}$ NMR spectrum (Fig. 3). Termination also occurs after 2,1-insertion of allylbenzene: the elimination of a benzylic $\beta$-hydride forms a terminal styryl $\left(\mathrm{PhCH}^{\mathrm{a}}=\mathrm{CH}^{\mathrm{b}}-\right)$ group, and the elimination of an internal $\beta$-hydride forms the $\mathrm{PhCH}_{2}^{\mathrm{e}}{ }_{2} \mathrm{CH}^{\mathrm{f}}=\mathrm{CH}^{\mathrm{g}}$ - group. These observations suggested that not only propylene but also allylbenzene underwent 2,1-insertion into the polymer chain.

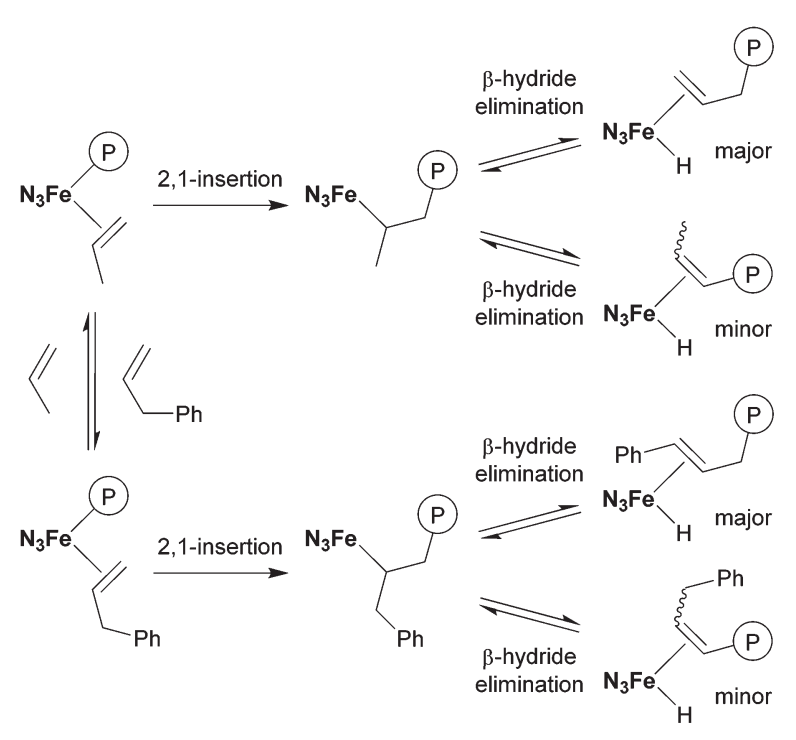

Scheme 2 Termination mechanism of the copolymerisation of propylene with allylbenzene. 

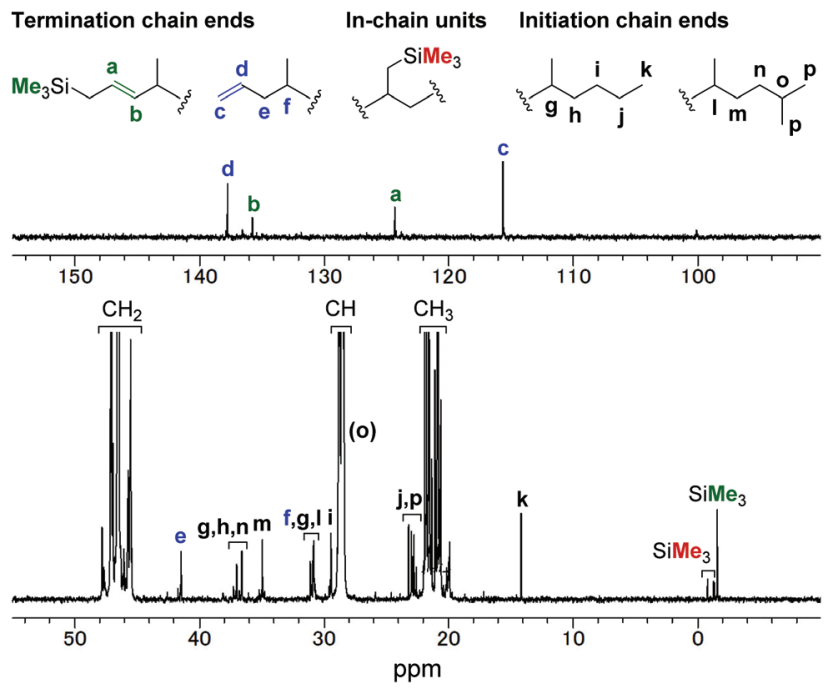

Fig. $4{ }^{13} \mathrm{C}$ NMR spectrum of propylene/allyl(trimethyl)silane copolymer (entry 7 in Table 2).

Copolymerisation of propylene with allylsilanes was also investigated. The copolymerisation reactions in the presence of $0.40 \mathrm{~mL}$ of allyl(trimethyl)silane (entry 7), allyl(dimethyl)(phenyl)silane (entry 8), and allyl(triethoxy)silane (entry 9) afforded the corresponding copolymers with comonomer incorporations of $2.1 \%, 1.7 \%$, and $0.30 \%$, respectively. In the ${ }^{1} \mathrm{H}$ and ${ }^{13} \mathrm{C}$ NMR spectra (Fig. 4) of the propylene/allyl(trimethyl)silane copolymer (entry 7), olefinic signals that correspond to terminal and internal carbon-carbon double bonds were observed. The terminal $\mathrm{C}=\mathrm{C}$ bond is derived from the presence of an allyl group ( $\mathrm{c}$ and $\mathrm{d}$ in Fig. 4). We assigned the internal $\mathrm{C}=\mathrm{C}$ bond to a $\mathrm{Me}_{3} \mathrm{SiCH}_{2} \mathrm{CH}=\mathrm{CH}$ - group generated by $\beta$-hydride elimination after insertion of allyl(trimethyl)silane. This assignment is based on the fact that the integral ratio of the internal olefinic carbons and the predominant signal of the trimethylsilyl group was found to be $c a .1: 1$ on the basis of quantitative ${ }^{13} \mathrm{C}$ NMR analysis (Fig. S25 $\dagger$ ) and that the methylene proton next to the $\mathrm{C}=\mathrm{C}$ bond was observed at an unusually high field in the ${ }^{1} \mathrm{H}$ NMR spectrum (Fig. S23 $\dagger$ ). Regarding the methyl group on the trimethylsilyl group, three other minor signals were observed around $-1.5 \mathrm{ppm}\left(\mathrm{SiMe}_{3}\right.$ shown as red). Although we could not assign all the signals, partly because they overlapped, we assumed that the three signals corresponding to the trimethylsilyl group are derived from in-chain incorporation of allyl(trimethyl)silane.

The structure of the propylene/allyl(dimethyl)(phenyl)silane copolymer was similar to that of the propylene/allyl(trimethyl) silane copolymer. In the ${ }^{1} \mathrm{H}$ NMR (Fig. S27†) and ${ }^{13} \mathrm{C}$ NMR (Fig. S28 and S29†) spectra, the signals of the phenyl and methyl groups of (dimethyl)(phenyl)silyl groups were clearly observed, suggesting that the allylsilane was successfully incorporated into the polymer. Olefinic signals assignable to an allyl group, i.e., a $\mathrm{Me}_{2} \mathrm{PhSiCH}_{2} \mathrm{CH}=\mathrm{CH}-$ group, were observed (Fig. S29†). As methyl carbons of the (dimethyl)(phenyl)silyl group, six signals were observed around $-2.8 \mathrm{ppm}$ in the
${ }^{13} \mathrm{C}$ NMR spectrum, indicating the presence of different types of incorporated structure. The five signals other than that of the $\mathrm{Me}_{2} \mathrm{PhSiCH}_{2} \mathrm{CH}=\mathrm{CH}-$ group possibly correspond to in-chain incorporation and saturated initiating chain-end structure.

Finally, in the case of allyl(triethoxy)silane, only a terminal allyl group was observed as a major chain end group in the ${ }^{13} \mathrm{C}$ NMR spectrum (Fig. S32 $\dagger$ ). Although the signals of the ethoxy moiety were observed in NMR analysis, the low content of the silyl groups made it difficult to fully determine the microstructure of the copolymer.

In these copolymerisations, both the catalytic activity and $M_{\mathrm{n}}$ value of the obtained copolymers were lower than those obtained by propylene homopolymerisation. This may be due in part to the role of these comonomers as chain transfer reagents that induce $\beta$-hydride elimination caused by retarding the next monomer insertion after incorporation of bulky functional groups into the polymer chain.

\section{Conclusions}

In summary, we synthesised a series of bis(imino)pyridine ligands and their iron complexes, and investigated their catalytic activity for propylene polymerisation and propylene/allyl monomer copolymerisation. In these polymerisations, the molecular weights are to some extent correlated with the steric factors of the imine substituents on the bis(imino)pyridine ligands. Thus, the highest molecular weight of polypropylene of $M_{\mathrm{n}}=6.6 \mathrm{kDa} \mathrm{mol}^{-1}$ was achieved by using $2 \mathrm{~g}$ bearing pentan3-yl substituted aryl groups. Once the substituent becomes too bulky, however, the catalytic activity was severely decreased. Copolymerisation of various ally monomers with propylene were examined to find that the copolymerisation with allylbenzene and allylsilanes afforded the corresponding copolymers. Although the allyl monomers were incorporated mainly into the terminal chain-end position of the copolymer, this report represents the first example of iron/bis(imino)pyridine-catalysed copolymerisation of propylene with allyl monomers.

\section{Conflict of interest}

The authors declare no competing financial interests.

\section{Acknowledgements}

This work was partially supported by JST and CREST. S. I. thanks financial support from the TonenGeneral Sekiyu Foundation.

\section{Notes and references}

1 (a) M. Gahleitner and C. Paulik, in Ullmann's Encyclopedia of Industrial Chemistry, Wiley-VCH, Weinheim, 2014, DOI: 
10.1002/14356007.o21_o04.pub2; (b) Polypropylene Handbook, ed. N. Pasquini, Carl Hanser Verlag, Munich, 2nd edn, 2005.

2 (a) M. Rätzsch, M. Arnold, E. Borsig, H. Bucka and N. Reichelt, Prog. Polym. Sci., 2002, 27, 1195-1282; (b) R. P. Singh, Prog. Polym. Sci., 1992, 17, 251-281; (c) J. Jagur-Grodzinski, Prog. Polym. Sci., 1992, 17, 361-415.

3 (a) L. K. Johnson, C. M. Killian and M. Brookhart, J. Am. Chem. Soc., 1995, 117, 6414-6415; (b) L. K. Johnson, S. Mecking and M. Brookhart, J. Am. Chem. Soc., 1996, 118, 267-268; (c) S. Mecking, L. K. Johnson, L. Wang and M. Brookhart, J. Am. Chem. Soc., 1998, 120, 888-899.

4 E. Drent, R. van Dijk, R. van Ginkel, B. van Oort and R. I. Pugh, Chem. Commun., 2002, 744-745.

5 (a) L. S. Boffa and B. M. Novak, Chem. Rev., 2000, 100, 1479-1494; (b) S. D. Ittel, L. K. Johnson and M. Brookhart, Chem. Rev., 2000, 100, 1169-1204; (c) A. Berkefeld and S. Mecking, Angew. Chem., Int. Ed., 2008, 47, 2538-2542; (d) A. Nakamura, S. Ito and K. Nozaki, Chem. Rev., 2009, 109, 5215-5244; (e) S. Ito and K. Nozaki, Chem. Rec., 2010, 10, 315-325; $(f)$ A. Nakamura, T. M. J. Anselment, J. Claverie, B. Goodall, R. F. Jordan, S. Mecking, B. Rieger, A. Sen, P. W. N. M. van Leeuwen and K. Nozaki, Acc. Chem. Res., 2013, 46, 1438-1449; (g) B. P. Carrow and K. Nozaki, Macromolecules, 2014, 47, 2541-2555.

6 Z. Guan, P. M. Cotts, E. F. McCord and S. J. McLain, Science, 1999, 283, 2059-2062.

7 A. E. Cherian, J. M. Rose, E. B. Lobkovsky and G. W. Coates, J. Am. Chem. Soc., 2005, 127, 13770-13771.

8 J. D. Azoulay, H. Gao, Z. A. Koretz, G. Kehr, G. Erker, F. Shimizu, G. B. Galland and G. C. Bazan, Macromolecules, 2012, 45, 4487-4493.

9 R. Nakano and K. Nozaki, J. Am. Chem. Soc., 2015, 137, 10934-10937.

10 (a) B. L. Small, M. Brookhart and A. M. A. Bennett, J. Am. Chem. Soc., 1998, 120, 4049-4050; (b) G. J. P. Britovsek, M. Bruce, V. C. Gibson, B. S. Kimberley, P. J. Maddox, S. Mastroianni, S. J. McTavish, C. Redshaw, G. A. Solan, S. Strömberg, A. J. P. White and D. J. Williams, J. Am. Chem. Soc., 1999, 121, 8728-8740.

11 B. L. Small and M. Brookhart, Macromolecules, 1999, 32, 2120-2130.

12 C. Pellecchia, M. Mazzeo and D. Pappalardo, Macromol. Rapid Commun., 1998, 19, 651-655.

13 (a) B. L. Small, Acc. Chem. Res., 2015, 48, 2599-2611; (b) W. Zhang, W.-H. Sun and C. Redshaw, Dalton Trans., 2013, 42, 8988-8997; (c) V. C. Gibson, C. Redshaw and G. A. Solan, Chem. Rev., 2007, 107, 1745-1776; (d) C. Bianchini, G. Giambastiani, I. G. Rios, G. Mantovani, A. Meli and A. M. Segarra, Coord. Chem. Rev., 2006, 250, 1391-1418; (e) V. C. Gibson and S. K. Spitzmesser, Chem. Rev., 2003, 103, 283-315; (f) G. J. P. Britovsek, V. C. Gibson and D. F. Wass, Angew. Chem., Int. Ed., 1999, 38, 428-447.

14 For experimental studies, see: (a) S. T. Babik and G. Fink, J. Mol. Catal. A: Chem., 2002, 188, 245-253; (b) S. T. Babik and G. Fink, J. Organomet. Chem., 2003, 683, 209-219; (c) B. L. Small and R. Schmidt, Chem. - Eur. J., 2004, 10, 1014-1020; (d) G. Fink and S. T. Babik, Kinet. Catal., 2006, 47, 198-206; (e) A. Rodríguez-Delgado, J. Cámpora, A. M. Naz, P. Palma and M. L. Reyes, Chem. Commun., 2008, 5230-5232; $(f)$ A. Behr, N. Rentmeister, D. Möller, J. Vosberg, S. Peitz and D. Maschmeyer, Catal. Commun., 2014, 55, 38-42.

15 For theoretical studies, see: $(a)$ L. Deng, P. Margl and T. Ziegler, J. Am. Chem. Soc., 1999, 121, 6479-6487; (b) D. V. Khoroshun, D. G. Musaev, T. Vreven and K. Morokuma, Organometallics, 2001, 20, 2007-2026; (c) R. Raucoules, T. de Bruin, P. Raybaud and C. Adamo, Organometallics, 2009, 28, 5358-5367.

16 Y. Ota, S. Ito, J. Kuroda, Y. Okumura and K. Nozaki, J. Am. Chem. Soc., 2014, 136, 11898-11901.

17 For a review, see: D. H. Camacho and Z. Guan, Chem. Commun., 2010, 46, 7879-7893.

18 (a) J. E. Steves, M. D. Kennedy, K. P. Chiang, W. S. Kassel, W. G. Dougherty, T. J. Dudley and D. L. Zubris, Dalton Trans., 2009, 1214-1222; (b) F. Pelascini, F. Peruch, P. J. Lutz, M. Wesolek and J. Kress, Eur. Polym. J., 2005, 41, 1288-1295; (c) L.-H. Guo, H.-Y. Gao, L. Zhang, F.-M. Zhu and Q. Wu, Organometallics, 2010, 29, 2118-2125; (d) J. Yu, H. Liu, W. Zhang, X. Hao and W.-H. Sun, Chem. Commun., 2011, 47, 3257-3259.

19 H. W. Boone, P. S. Athey, M. J. Mullins, D. Philipp, R. Muller and W. A. Goddard, J. Am. Chem. Soc., 2002, 124, 8790-8791.

20 (a) S. Ito, M. Kanazawa, K. Munakata, J. Kuroda, Y. Okumura and K. Nozaki, J. Am. Chem. Soc., 2011, 133, 1232-1235; (b) S. Ito, Y. Ota and K. Nozaki, Dalton Trans., 2012, 41, 13807-13809.

21 S. Meiries, G. Le Duc, A. Chartoire, A. Collado, K. Speck, K. S. A. Arachchige, A. M. Z. Slawin and S. P. Nolan, Chem. - Eur. J., 2013, 19, 17358-17368.

22 CCDC 1416774 (2c), 1416775 (2d'), 1416776 (2g) contain the supplementary crystallographic data for this paper.

23 (a) L. Guo, H. Gao, L. Zhang, F. Zhu and Q. Wu, Organometallics, 2010, 29, 2118-2125; (b) Y. Chen, R. Chen, C. Qian, X. Dong and J. Sun, Organometallics, 2003, 22, 4312-4321.

24 Small and Brookhart achieved the highest value of $67 \%$ using ligand bearing $\mathrm{R}^{1}=\mathrm{R}^{3}=\mathrm{Me}$ and $\mathrm{R}^{2}=\mathrm{R}^{4}=$ iPr. See ref. 11 .

25 V. Busico, R. Cipullo, G. Monaco, M. Vacatello and A. L. Segre, Macromolecules, 1997, 30, 6251-6263.

26 (a) S. Lipponen, M. Lahelin and J. Seppälä, Eur. Polym. J., 2009, 45, 1179-1189; (b) C. Ruiz-Orta, J. P. Fernandez-Blazquez, A. M. Anderson-Wile, G. W. Coates and R. G. Alamo, Macromolecules, 2011, 44, 3436-3451.

27 A. Grassi, A. Zambelli, L. Resconi, E. Albizzati and R. Mazzocchi, Macromolecules, 1988, 21, 617-622.

28 M. Mitani, R. Furuyama, J. Mohri, J. Saito, S. Ishii, H. Terao, T. Nakano, H. Tanaka and T. Fujita, J. Am. Chem. Soc., 2003, 125, 4293-4305.

29 (a) P. D. Hustad, J. Tian and G. W. Coates, J. Am. Chem. Soc., 2002, 124, 3614-3621; (b) L. Resconi, L. Cavallo, A. Fait and F. Piemontesi, Chem. Rev., 2000, 100, 1253-1345. 
30 Although the coupling constants could not be accurately determined due to broadening of signals, the coupling pattern is also consistent with the assignments.

31 Some polymerizations were performed using 2a as a catalyst. See ESI $\dagger$ for the data.

32 (a) K. W. Doak, in Encyclopedia of Polymer Science and Engineering, ed. H. F. Mark, N. M. Bikales, C. G. Overberger and G. Menges, Wiley, New York, 2nd edn, 1986, vol. 6, pp. 386-429; (b) D. Jeremic, in Ullmann's Encyclopedia of Industrial Chemistry, Wiley-VCH, Weinheim, 2014, DOI: 10.1002/ 14356007.a21_487.pub3.

33 See ESI† for details.

34 For homopolymerisation of allylbenzene, see: (a) G. F. D'alelio, A. B. Finestone, L. Taft and T. J. Miranda, J. Polym. Sci., 1960, 45, 83-89; (b) D.-J. Byun, D.-K. Shin, J. Jiu and S. Y. Kim, Polym. Bull., 1999, 42, 265-272; (c) D.-J. Byun, D.-K. Shin and S. Y. Kim, Polym. Bull., 1999, 42, 301-307.

35 For copolymerisation of allylbenzene with ethylene, see: (a) L.-M. Tang, Y.-G. Li, W.-P. Ye and Y.-S. Li, J. Polym. Sci., Part A: Polym. Chem., 2006, 44, 5846-5854; (b) L.-M. Tang, T. Hu, L. Pan and Y.-S. Li, J. Polym. Sci., Part A: Polym. Chem., 2005, 43, 6323-6330; (c) K. R. Kumar and S. Sivaram, Polym. Int., 2001, 50, 367-374; (d) D.-J. Byun and S. Y. Kim, Macromolecules, 2000, 33, 1921-1923; (e) D.-J. Byun, D.-K. Shin and S. Y. Kim, Macromol. Rapid Commun., 1999, 20, 419-422.

36 For copolymerisation of allylbenzene with propylene, see: I. Hayashi, Kogyo Kagaku Zasshi, 1967, 70, 735-738.

37 For homopolymerisation of allylsilane, see: (a) G. Natta, G. Mazzanti, P. Longi and F. Bernardini, J. Polym. Sci., 1958, 31, 181-183; (b) R. Ziegler, L. Resconi, G. Balbontin, G. Guerra, V. Venditto and C. De Rosa, Polymer, 1994, 35, 4648-4655; (c) S. Habaue, H. Baraki and Y. Okamoto, Macromol. Chem. Phys., 1998, 199, 22112215; (d) J.-Y. Lee, M.-C. Shiao, F.-Y. Tzeng, C.-H. Chang, C.-K. Tsai and J.-C. Tsai, Macromolecules, 2012, 45, 27202730 .

38 For copolymerisation of allylsilanes with ethylene, see: (a) S. H. Lipponen and J. V. Seppälä, Organometallics, 2011, 30, 528-533; (b) J. Liu and K. Nomura, Macromolecules, 2008, 41, 1070-1072; (c) S. B. Amin and T. J. Marks, J. Am. Chem. Soc., 2007, 129, 2938-2953; (d) N. Naga, Macromol. Chem. Phys., 2005, 206, 1959-1966.

39 For copolymerisation of allylsilanes with propylene, see: (a) N. Naga, J. Polym. Sci., Part A: Polym. Chem., 2006, 44, 6083-6093; (b) P. Longi, F. Greco and U. Rossi, Macromol. Chem. Phys., 1968, 116, 113-121. 